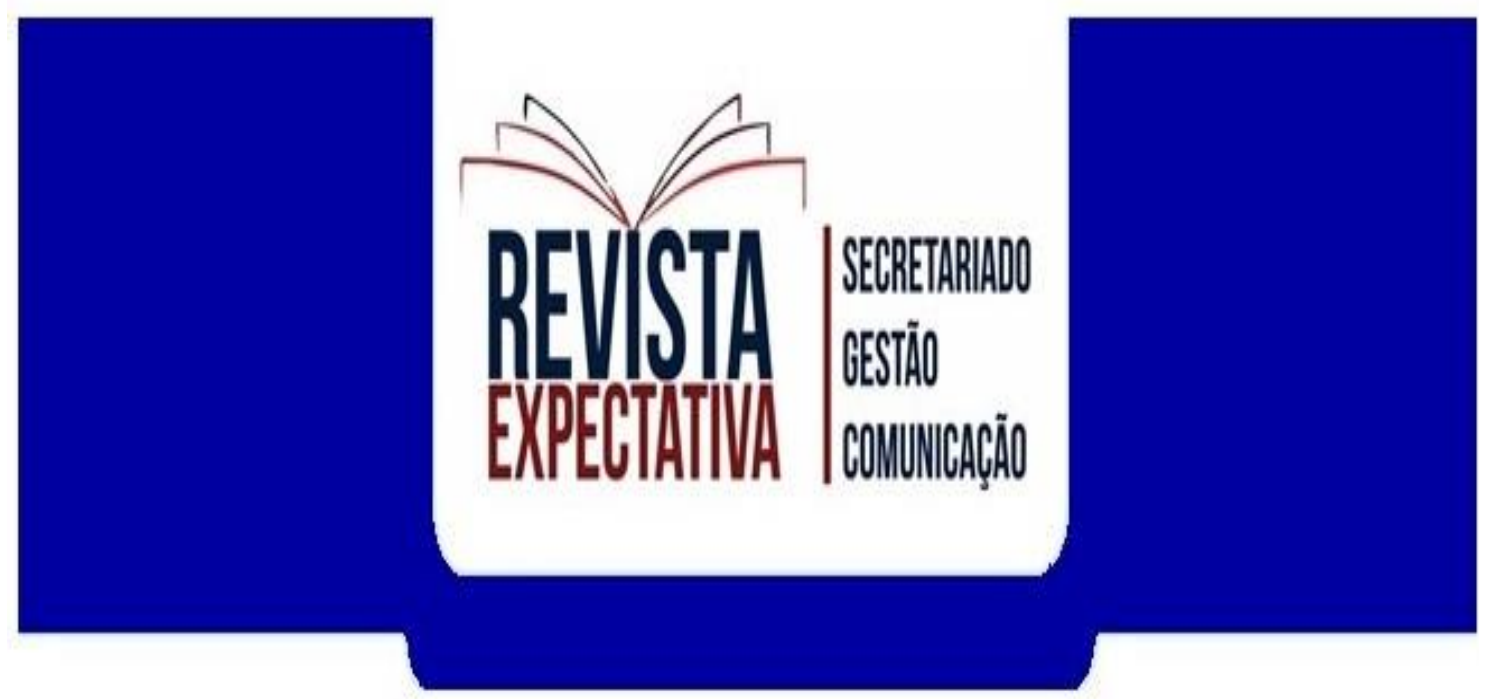

\title{
PELO AMOR OU PELA DOR: A PERCEPÇÃO AMBIENTAL DE ESTUDANTES UNIVERSITÁRIOS BRASILEIROS
}

Waleska Reali de Oliveira Braga ${ }^{1}$, Sérgio Silva Braga Junior², Dirceu da Silva ${ }^{3}$

Resumo: A Educação Ambiental e a legislação ambiental buscam por meio da conscientização e da reflexão sobre as questões socioambientais transformar indivíduos em "cidadãos ambientais". Estudos demonstram que o nível de conscientização ambiental de cada indivíduo está diretamente relacionado ao grau de percepção ambiental e que este, reflete diretamente no comportamento ambiental do indivíduo. Assim, o objetivo da pesquisa foi verificar se a percepção ambiental dos estudantes universitários de administração reflete no conhecimento sobre as questões ambientais. Para tanto, foi realizada uma pesquisa junto a uma universidade do estado do Mato Grasso do Sul e três universidades do estado de São Paulo com um total de 527 respondentes, sendo duas universidades públicas e duas privadas. Para análise de dados, foi utilizada a modelagem de equações estruturais por meio do software SmartPLS 2.0 M3. O resultado indica que a percepção ambiental do universitário tem foco, principalmente, na reciclagem, na economia de água e energia e na redução do consumo.

1 Doutoranda em Geografia pela UNESP/FCT, Mestre em Agronegócio e Desenvolvimento pela UNESP/FCE e Graduada em Geografia pela UNESP/FCT. https://orcid.org/0000-0002-7148-1935

${ }^{2}$ Doutor em Administração pela UNINOVE, Mestre em Administração de Organizações pela USP/FEARP e Graduado em Administração pela Unitoledo. http://orcid.org/00000002-4979-1988

3 Doutor em Educação pela USP, Mestre e Graduado em Física pela USP. http://orcid.org/0000-0003-3267-511X

Editor: Cezar Roberto Versa

Recebido em: 19/12/2019 - Revisado em: 12/03/2020 - Aprovado em: 25/05/2020

Revista Expectativa- e-ISSN 1982-3029 - v.19 - n.1 - jan./jun. - 2020 
Palavras-chave: Educação Ambiental. Percepção Ambiental. Modelagem Quantitativa.

\begin{abstract}
Environmental Education and environmental legislation seek to raise awareness and reflection on social and environmental issues as "environmental citizens." Studies show that the level of environmental awareness of each is directly relational to the degree of environmental perception and that this, directly reflects on the environmental behavior of the individual. Thus, the objective of the research was to verify if the environmental perception of the university students of administration reflects in the know about the environmental questions. Therefore, a survey was carried out with a university in the state of Mato Grosso do Sul and three universities in the state of São Paulo, with a total of 527 respondents, two public universities and two private universities. For data analysis, the modeling of structural equations using the software SmartPLS $2.0 \mathrm{M} 3$ it was used. The result indicates that the environmental perception of the university has the primary focus on recycling, water, and energy saving and consumption reduction.
\end{abstract}

Keywords: Environmental education. Environmental Perception. Quantitative Modeling.

\title{
1 INTRODUÇÃO
}

Um dos maiores desafios vivenciados pela humanidade desde meados do século XX tem sido o enfrentamento de problemas ambientais. Os impactos causados pela ação do ser humano no meio ambiente e, por decorrência, a sua própria sociedade, tem suscitado cada vez mais um chamamento à busca de soluções que possam conciliar o consumo com a preservação e conservação ambiental.

A sociedade vem passando por fases distintas de apropriação da natureza para suprir necessidades de cada época. No início, necessidades imediatas relacionadas à subsistência, depois necessidades de produção de mercadorias e, atualmente, vivendo a apropriação da natureza para suprir as necessidades de consumo.

Assim, o crescente consumo de produtos cujos processos de produção exercem forte pressão sobre os recursos naturais, gerando rejeitos que, quando dispostos de maneira inadequada, podem causar acidentes ambientais com repercussão negativa, reforçam os debates ambientais acerca da 
cobrança de soluções por parte da sociedade, seja por meio da conscientização espontânea, seja por meio da criação de normas que disciplinem o comportamento, conforme apresentam Barbieri e Silva (2012).

Constatado um cenário de agravamento de problemas ambientais e sociais, percebidos desde a Conferência de Estocolmo (NASCIMENTO, 2012), vive-se em uma sociedade de risco ambiental, e é imprescindível transformar em prática o discurso a favor do meio ambiente.

A criação de leis e normas ambientais reforça essa conscientização, já que tais aparatos legais devem ser entendidos como o aprofundamento no conhecimento coletivo acerca dos problemas ambientais refletidos em atitudes da sociedade, segundo Portilho (2010). Neste sentido, os cidadãos e os gestores públicos e privados são chamados a repensar o seu estilo de vida e a forma de conduzir seus negócios assumindo responsabilidades que vão além da sua formação disciplinar.

Uma vez que a percepção ambiental está ligada à conscientização e essa, por sua vez, pode ocorrer por meio da educação nas diversas etapas do ensino formal, inclusive no ensino superior, a presente pesquisa buscou responder a seguinte questão: Será que a percepção ambiental de estudantes universitários do curso de administração reflete sobre as questões ambientais?

Respondendo esta questão, o objetivo da presente pesquisa foi verificar se a percepção ambiental dos estudantes universitários de administração estão sendo refletidas no conhecimento sobre as questões ambientais por meio das seguintes hipóteses:

H1: A Percepção Ambiental dos universitários reflete positivamente no conhecimento das Leis Ambientais;

H2: A Percepção Ambiental dos universitários reflete positivamente no Relacionamento com a Natureza;

H3: A Percepção Ambiental dos universitários reflete positivamente na preocupação com a Preservação da Natureza;

H4: A Percepção Ambiental dos universitários reflete positivamente na disposição em dividir a responsabilidade ambiental (Responsabilidade Compartilhada); 
Para verificar as hipóteses, foi realizada uma survey em uma universidade do estado do Mato Grasso do Sul e três universidades do estado de São Paulo com um total de 527 respondentes, sendo duas universidades públicas e duas privadas. Os resultados demonstraram que a percepção ambiental que, teoricamente, o aluno carrega do ensino fundamental e adquire no ensino superior ainda é limitada na reciclagem, na economia de água e energia e na redução do consumo, refletindo de forma positiva sobre alguns aspectos legais, sobre o contato com a natureza e sobre os aspectos de preservação ambiental e negativamente sobre a responsabilidade compartilhada, onde, pode-se inferir que os estudantes tenham a percepção de que "cuidar do meio ambiente não é problema deles".

\section{REFERENCIAL TEÓRICO}

\subsection{UMA BREVE CONSTRUÇÃO SOBRE A PERCEPÇÃO ATÉ A PERCEPÇÃO AMBIENTAL}

Segundo Simões e Tiedemann (1985), os estudos sobre a percepção humana iniciaram em 1879, quando Wilhelm Wundt (1832-1920), considerado o pai da psicologia científica fundou, em 1879, em Leipzig - Alemanha, o primeiro laboratório de psicologia experimental com foco no desenvolvimento de estudos sobre essa temática, considerando a percepção um dos principais temas da psicologia científica.

A partir daí, sugiram explicações para a construção do conceito. Para Forgus (1971) a percepção é definida como um processo para extrair informação a partir da recepção, aquisição, assimilação e utilização do conhecimento adquirido gerando aprendizagem e pensamento.

Para Tuan (1980, p. 4), a percepção "é tanto a resposta dos sentidos aos estímulos externos, como a atividade proposital em que certos fenômenos são claramente registrados enquanto outros são bloqueados".

Buono e Bowditch (1992) consideram que a percepção é o processo de compreender como um indivíduo reage às sensações, que são os estímulos 
físicos dos sentidos, visão, audição, paladar, tato e olfato. Os autores também consideram como percepção a organização, por meio do conhecimento, dessas sensações, ajudando a explicar os "como e porquês" do comportamento. Ou seja, a percepção refere-se à maneira como as mensagens desses órgãos são interpretadas para dar significado ao nosso meio ambiente.

Para Chauí (2002), a percepção envolve toda nossa personalidade, nossa história pessoal, nossa afetividade, nossos desejos, isto é, a percepção é uma maneira fundamental dos seres humanos estarem no mundo, é uma comunicação, uma interpretação a partir da estrutura de relações entre nosso corpo e o mundo.

A percepção é claramente mais do que o processo no qual os estímulos vencem os sentidos, é o início do processamento de informações, a interpretação dos estímulos aos quais se presta a atenção de acordo com a conformação mental existente, que são as atitudes, experiência e motivação (BAKER, 2005).

Rodrigues et al. (2012) relatam ter sido em meados dos anos 60 que as análises da percepção começaram a ser discutidas também na área do meio ambiente, sendo que um exemplo da evolução dos estudos em percepção ambiental, foi à criação pela UNESCO, em 1973, do Projeto 13, "Percepção de Qualidade Ambiental", ressaltando a importância da pesquisa em percepção ambiental para o planejamento do meio ambiente.

Davidoff (2001) ao tratar percepção na sua vertente ambiental, nos diz que essa é pré-requisito para se atingir diferentes níveis de conscientização ambiental, de modo que a somatória de percepção e conscientização ambiental, com conhecimento científico, são os vetores com potencial para a promoção da efetiva conservação ambiental. Para este autor a percepção implica na interpretação tornando-se individual. Como consequência, o meio em que o indivíduo está inserido, bem como suas motivações, expectativas, valores, emoções e experiências influenciam na percepção (DAVIDOFF, 2001).

Para quantificar um fenômeno ambiental é necessário percebê-lo. Para o avanço do conhecimento científico, é essencial estudar os indicadores ambientais e trocar experiências (MAIA et al., 2001). 
Segundo Brandalise et al. (2009) a percepção pode ser considerada uma variável interventora, que influencia o processo de tomada de decisão sobre qualquer questão ambiental, entretanto, apesar de intervir na tomada de decisão, a percepção é resultado da educação ambiental que a sociedade possui. Sendo que, a partir do conhecimento e da percepção ambiental, as atitudes e o comportamento poderão ser modificados.

Em se tratando da percepção ambiental, Macedo (2005) afirma que essa pode ser usada como um instrumento para se identificar como acontece a relação entre o ser humano e a natureza, e para compreender o nível de conscientização desses quanto à problemática ambiental.

Preservar o meio ambiente então, está totalmente relacionado com a percepção de fazer parte do meio, sentindo-se parte dele e consequentemente tendo ações que influenciarão o equilíbrio e a relação sociedade/natureza.

\subsection{PELA DOR: LEGISLAÇÃO AMBIENTAL}

O ser humano é um ser essencialmente social. E por esse motivo é necessário que haja um sistema de regras para pautar essa convivência em sociedade. Para Kelsen (2005), o anseio por justiça é como o eterno anseio do homem pela felicidade. Neste caminho, não se pode buscar a felicidade sozinho, portanto, procura-se em sociedade. E a justiça, é a felicidade social.

Como paz e justiça são conceitos subjetivos, cria-se, por vontade dos homens, um sistema de normas que permita a convivência social sem o emprego da força, afinal, o viver em comunidade só será possível se cada indivíduo respeitar certos interesses - vida, saúde, liberdade e propriedade de todos os outros (CASABONA, 2007).

No caso do Direito Ambiental, Farias et al. (2013) afirmam que é um ramo da ciência jurídica que não visa simplesmente regular as relações humanas que se utilizam ou possam se utilizar dos recursos naturais, mas sim promover a proteção e a melhoria da qualidade ambiental.

Teoricamente, a legislação ambiental pode refletir pontos que não foram atingidos pela mudança de comportamento por meio da percepção espontânea do cidadão, e que, de forma coercitiva, trazem regras para disciplinar ou 
modificar o comportamento e proteger aquilo que se encontra ameaçado. Conforme Milaré (2015, p.232), “começou, então, o legislador a transfundir em normas os valores de convivência harmoniosa do homem com a natureza, ensejando o aparecimento de uma nova disciplina jurídica - o Direito ambiental".

Apesar do grande número de normas e leis existentes para disciplinar e orientar a relação ser humano/natureza, percebe-se que constantemente novas leis são criadas ou as estabelecidas são revisadas como forma de acompanhar as necessidades da sociedade.

Farias (2006) afirma que o aparecimento de novas tecnologias e a evolução da sociedade fazem surgir diariamente novas situações capazes de interferir na qualidade do meio ambiente e que, por esta questão, o Direito Ambiental não pode deixar de ser regulador.

Se considerar que normas são oriundas de demandas da sociedade, as quais surgem para regulamentar as necessidades sociais e controlar os comportamentos e ações dos indivíduos de acordo com os princípios desta sociedade, é possível, por meio de um apanhado das principais normas jurídicas ambientais (leis ambientais) instituídas num recorte a partir da Constituição Federal de 1988, ter uma visão geral dos pontos nos quais foi percebida a necessidade de alguma intervenção para harmonizar a relação ser humano/ambiente.

\subsection{PELO AMOR: EDUCAÇÃO AMBIENTAL}

A educação como forma de estímulo de raciocínio, de transmissão de conhecimento de uma geração a outra, de ampliação de conhecimentos é um processo contínuo que dura à vida toda (BRANDÃO, 2006). Brandão (2006) ainda afirma que ninguém escapa da educação. Na rua, em casa, na igreja ou na escola, de um modo ou de muitos, todos nós envolvemos pedaços da vida com ela: para aprender, para ensinar, para aprender-e-ensinar.

Moran (2007, p. 14 -16) define a Educação como sendo: "[...] a soma de todos os processos de transmissão do conhecido, do culturalmente adquirido e de aprendizagem de novas ideias, procedimentos, soluções, realizados por 
pessoas, grupos, instituições, organizada ou espontaneamente, formal ou informalmente".

No que se refere à Educação Ambiental (EA), esta surge como uma tentativa de mudar comportamentos em prol de educar para as questões ambientais, capacitando a sociedade para a defesa ativa do meio ambiente.

\begin{abstract}
Ressalte-se que a Educação Ambiental surgiu como resposta à preocupação da sociedade com o futuro da vida. Mas, dentro do contexto atual, surge como um instrumento no processo de mudança dos comportamentos, a fim de despertar as pessoas para os problemas que os modelos de desenvolvimento econômico dos séculos passados causaram e ainda afetam direta ou indiretamente a qualidade de vida, procurando trocar comportamentos degradadores por relacionamentos harmônicos entre homem e meio ambiente. (DIAS; MARQUES; DIAS, 2016, p. 23-24)
\end{abstract}

Num contexto de agravamento de problemas ambientais, a EA tem um papel fundamental na formação de cidadãos ambientais, enriquecendo os meios de acesso a informações que possam alterar o atual quadro de degradação ambiental.

\begin{abstract}
Quando nos referimos à educação ambiental, situamo-na em contexto mais amplo, o da educação para a cidadania, configurandoa como elemento determinante para a consolidação de sujeitos cidadãos. O desafio do fortalecimento da cidadania para a população como um todo, e não para um grupo restrito, concretiza-se pela possibilidade de cada pessoa ser portadora de direitos e deveres, e de se converter, portanto, em ator co-responsável na defesa da qualidade de vida. (JACOBI, 2003, p.195)
\end{abstract}

Leonardi (1997) esclarece que em vários documentos internacionais enfatiza-se a importância da EA, entre outros motivos, por sua relação com o exercício da cidadania, o que demonstra seu compromisso original com a formação da cultura democrática.

Tanner (1978) lembra ainda que a EA busca um envolvimento público por meio de programas de ação que ensinem os educandos a serem cidadãos ativos numa democracia.

A Declaração de Tbillisi (1977), elaborada na Conferência Intergovernamental sobre Educação Ambiental, em Tbilisi - Geórgia nos traz a definição de EA como sendo, "um processo de reconhecimento de valores e clarificações de conceitos, objetivando o desenvolvimento das habilidades e mudança das atitudes em relação ao meio".

Para a Política Nacional de Educação Ambiental (1999), a EA é 
entendida como:

Os processos por meio dos quais o indivíduo e a coletividade constroem valores sociais, conhecimentos, habilidades, atitudes e competências voltadas para a conservação do meio ambiente, bem de uso comum do povo, essencial à sadia qualidade de vida e sua sustentabilidade. (BRASIL, 1999, art. $1^{\circ}$.)

Com relação aos objetivos da Educação Ambiental (EA), Rodríguez e Seolin (2014) afirmam que a EA tem como propósito básico incorporar a cultura ambiental nas percepções, comportamentos e nos imaginários das populações.

No tocante a EA, Sauvé (2005, p.17) explica que, apesar de todos terem uma preocupação comum com o meio ambiente, cada pesquisador, professor, pedagogo, animador, organismo, dentre outros, adotam diferentes discursos sobre a EA, cada um predica sua própria visão. Percebe-se que também na EA existe uma pluralidade de visões (percepções) sendo que umas foram dominantes nas primeiras décadas e outras correspondem a preocupações que surgiram recentemente. Ainda segundo Sauvé (2005, p. 18) entre as correntes de EA temos as que têm uma longa tradição sendo elas: a naturalista, a conservacionista/recursista, a resolutiva, a sistêmica, a científica, a humanista, moral/ética) e as correntes mais recentes: a holística, a biorregionalista, a práxica, a crítica, a feminista, a etnográfica, a da ecoeducação e da sustentabilidade.

Neste contexto, percebe-se que todas as tratativas voltadas à educação ambiental estão relacionadas a trazer, de forma sistêmica, o indivíduo para uma relação mais próxima e integrada com o meio que ocupa, buscando sua inserção na resolução de problemas cotidianos relacionados à natureza e à sociedade, exercitando sua atuação cidadã.

A educação ambiental como formação e exercício de cidadania refere-se a uma nova forma de encarar a relação do homem com a natureza, baseada numa nova ética, que pressupõe outros valores morais e uma forma diferente de ver o mundo e os homens. A educação ambiental deve ser vista como um processo de permanente aprendizagem que valoriza as diversas formas de conhecimento e forma cidadãos com consciência local e planetária. (JACOBI, 2003, p.198)

Institucionalizada no Brasil em 1999, por meio da Lei 9.795/99 - Política Nacional de Educação Ambiental (PNEA), o ensino sobre meio ambiente passa 
a se fazer presente na educação formal e não formal. De acordo com esta política entende-se por educação ambiental "os processos por meio dos quais o indivíduo e a coletividade constroem valores sociais, conhecimentos, habilidades, atitudes e competências para a conservação do meio ambiente".

A PNEA nos traz ainda que a educação ambiental é um componente essencial e deve estar presente em todos os níveis e modalidades do processo educativo, em caráter formal e não formal, incumbindo ao Poder Público, às instituições educativas, aos meios de comunicação de massa, as empresas e a sociedade como um todo, tornar esse processo educativo mais amplo.

Como direcionadora das ações de educação ambiental, a PNEA (1999), também nos traz quais são os princípios básicos da educação ambiental, sendo eles:

\footnotetext{
I - o enfoque humanista, holístico, democrático e participativo;

II - a concepção do meio ambiente em sua totalidade, considerando a interdependência entre o meio natural, o sócio-econômico e o cultural, sob o enfoque da sustentabilidade;

III - o pluralismo de idéias e concepções pedagógicas, na perspectiva da inter, multi e transdisciplinaridade;

IV - a vinculação entre a ética, a educação, o trabalho e as práticas sociais;

$\mathrm{V}$ - a garantia de continuidade e permanência do processo educativo;

$\mathrm{VI}$ - a permanente avaliação crítica do processo educativo;

VII - a abordagem articulada das questões ambientais locais, regionais, nacionais e globais;

VIII - o reconhecimento e o respeito à pluralidade e à diversidade individual e cultural.
}

Segundo Silva e Carvalho (2013), outro fato importante relacionado à questão ambiental é a elaboração dos Parâmetros Curriculares Nacionais PCN's, pelo Ministério da Educação e dos Desportos. Neste, a educação ambiental é introduzida como tema transversal nas diversas disciplinas do ensino formal, buscando contextualizar questões referentes aos problemas socioambientais, de acordo com as realidades locais e regionais, desenvolvendo conhecimentos teoricamente sistematizados e, trazendo questões ligadas ao mundo dos alunos.

Tamaio (2008) explica que:

Todo esse processo de institucionalização da EA no país está intimamente relacionado com o movimento ecológico, que surgiu da preocupação da sociedade com a qualidade da existência humana, com o futuro da vida. Foi no movimento ecológico que emergiu a compreensão da crise como uma questão de interesse público, isto é, 
que afeta a todos e da qual depende o futuro das sociedades (TAMAIO, 2008, p.24)

No estudo feito por Veiga et al. (2005), sobre a oferta da EA no ensino fundamental, nos anos de 2001 a 2004, em nível municipal, estadual e regional, pode-se constatar que no primeiro ano, $61,2 \%$ das escolas declararam que trabalham a temática no currículo, ou em projetos ou mesmo como disciplina específica, percentual que saltou para 94\% em 2004.

\section{PROCEDIMENTO METODOLÓGICO}

Visto que os estudos da percepção e do comportamento são abordados em vários campos de estudo possuindo uma dimensão bastante ampla, para este estudo será considerado as definições trazidas por Brandalise et al. (2009) e Macedo (2005), exposta anteriormente.

A partir da exploração teórica, para atingir o objetivo proposto, foi desenvolvido um questionário, validado e testado, conforme sugerido por Cooper e Schindler (2003) e DeVellis (2003), que foi aplicado junto a uma amostra de universitários do curso de administração em quatro Universidades brasileiras situadas nas regiões Sudeste e Centro Oeste, especificamente, nos estados do Mato Grosso do Sul e São Paulo, sendo duas universidades particulares e duas universidades públicas.

A coleta dos dados ocorreu entre os meses de agosto e novembro de 2017. Em todas as universidades a aplicação foi autorizada e os questionários foram aplicados presencialmente com 0 acompanhamento do docente que ministrava aula no momento da aplicação e sem a interferência do pesquisador.

O questionário aplicado foi composto por 36 questões fechadas sendo utilizada uma Escala Likert de cinco pontos entre discordância total e concordância total. Este método é definido por um conjunto de itens apresentados como afirmações para mensurar a reação do sujeito em três, cinco ou mais categorias (SAMPIERI et al., 2013).

Seguindo a recomendação de DeVellis (2003), o questionário (Quadros 1a e 1b) foi analisado e validado, em face e conteúdo, por especialistas 
reconhecidos por sua reputação e conhecimento do tema tratado. O questionário proposto foi enviado para a análise e validação de (10) dez especialistas, sendo que o número mínimo válido exigido, sugerido pelo autor, é de (5) cinco validações. Juntamente com o questionário, foi também encaminhado o objetivo da pesquisa para orientar a análise a ser realizada.

Dos dez especialistas que receberam os questionários para validação, cinco retornaram com sugestões de ajustes que, conforme a interpretação de cada um, feitos tais ajustes o objetivo da pesquisa seria plenamente atendido.

Quadro 1a - Questionário utilizado na pesquisa

\begin{tabular}{|c|c|c|}
\hline Constructo & Item & Questão \\
\hline \multirow{11}{*}{ 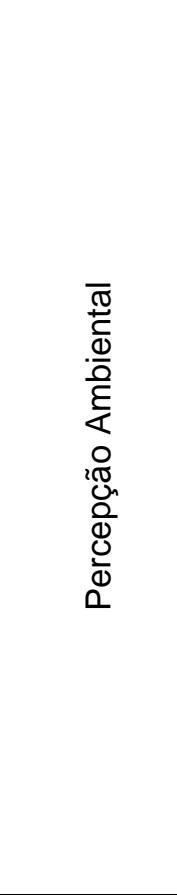 } & $\begin{array}{l}\text { Perce } \\
\text { p_1 }\end{array}$ & O consumismo agrava os problemas ambientais \\
\hline & $\begin{array}{l}\text { Perce } \\
\text { p_2 }\end{array}$ & $\begin{array}{l}\text { A reciclagem contribui para a diminuição dos problemas ambientais } \\
\text { gerados pelo uso abusivo dos recursos naturais }\end{array}$ \\
\hline & $\begin{array}{l}\text { Perce } \\
\text { p_3 }\end{array}$ & Sempre separo o lixo reciclável do não reciclável \\
\hline & $\begin{array}{l}\text { Perce } \\
\text { p_4 }\end{array}$ & $\begin{array}{l}\text { Sempre verifico se uma empresa está associada a algum problema } \\
\text { ambiental }\end{array}$ \\
\hline & $\begin{array}{l}\text { Perce } \\
\text { p } 5\end{array}$ & Sempre gasto pouco tempo no banho \\
\hline & $\begin{array}{l}\text { Perce } \\
p=6\end{array}$ & $\begin{array}{l}\text { Sempre apago as luzes, desligo TV e outros aparelhos quando saio do } \\
\text { ambiente }\end{array}$ \\
\hline & $\begin{array}{l}\text { Perce } \\
\text { p_7 }\end{array}$ & $\begin{array}{l}\text { Sempre procuro utilizar transporte público, carona, bicicleta ou a pé para } \\
\text { me deslocar para o trabalho ou escola }\end{array}$ \\
\hline & $\begin{array}{l}\text { Perce } \\
\text { p_8 }\end{array}$ & 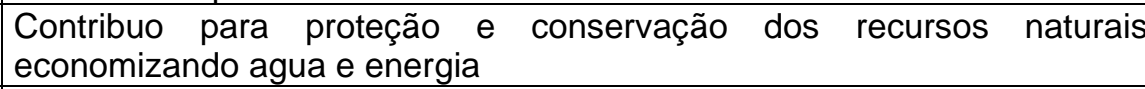 \\
\hline & $\begin{array}{l}\text { Perce } \\
\text { p_9 }\end{array}$ & $\begin{array}{l}\text { Estou disposto a fazer trabalhos voluntários em prol de causas } \\
\text { ambientais }\end{array}$ \\
\hline & $\begin{array}{l}\text { Perce } \\
\text { p_10 }\end{array}$ & Quando não tem lixeira por perto, levo o lixo comigo \\
\hline & $\begin{array}{l}\text { Perce } \\
\text { p_11 }\end{array}$ & $\begin{array}{l}\text { Procuro comprar produtos com produção local/regional, privilegiando a } \\
\text { economia local e contribuindo na redução de impactos ambientais }\end{array}$ \\
\hline \multirow{8}{*}{ 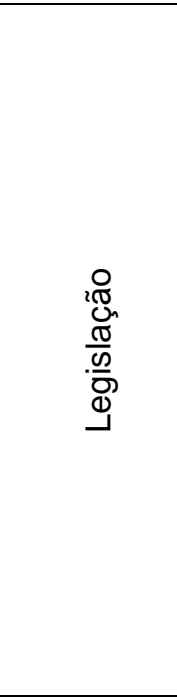 } & Lei_1 & $\begin{array}{l}\text { Se encontro um filhote de qualquer ave silvestre, não vejo problema em } \\
\text { levá-lo para casa ou entregar para algum conhecido }\end{array}$ \\
\hline & Lei_2 & $\begin{array}{l}\text { Não vejo problema em perfurar um poço ou captar água em um rio, sem } \\
\text { autorização, desde que seja para uso doméstico }\end{array}$ \\
\hline & Lei_3 & $\begin{array}{l}\text { Não vejo problema em descartar, embalagens de inseticidas, frascos de } \\
\text { remédios, remédios vencidos no lixo comum }\end{array}$ \\
\hline & Lei_4 & $\begin{array}{l}\text { As empresas sempre devem ter acesso limitado ao uso de água captada } \\
\text { em rios e poços }\end{array}$ \\
\hline & Lei_5 & $\begin{array}{l}\text { A caça e o tráfico de animais silvestres sempre devem ser punidos com } \\
\text { multa e prisão dos responsáveis }\end{array}$ \\
\hline & Lei_6 & $\begin{array}{l}\text { As empresas que utilizam água proveniente de poços ou faça captação } \\
\text { em rios sem a devida autorização devem ser penalizadas }\end{array}$ \\
\hline & Lei_7 & $\begin{array}{l}\text { Realizar manutenções preventivas nos veículos particulares e coletivos } \\
\text { contribuem para melhorar a qualidade do ar }\end{array}$ \\
\hline & Lei_8 & $\begin{array}{l}\text { As empresas que adquirem madeira, lenha, carvão e outros produtos de } \\
\text { origem vegetal sem a licença ambiental, estão contribuindo para o } \\
\text { desmatamento ilegal }\end{array}$ \\
\hline
\end{tabular}




\begin{tabular}{|c|c|c|}
\hline 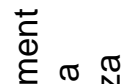 & $\begin{array}{l}\text { Rel_N } \\
\text { at_1 }\end{array}$ & Faz parte do meu lazer praticar esportes ao ar livre ligados a natureza \\
\hline 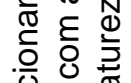 & $\begin{array}{l}\text { Rel_N } \\
\text { at } 2\end{array}$ & Tenho lembranças agradáveis de momentos de contato com a natureza \\
\hline$\frac{\pi}{\mathbb{d}} \circ z$ & $\begin{array}{l}\text { Rel_N } \\
\text { at } \overline{3}\end{array}$ & Sinto-me revigorado quando estou em contato com a natureza \\
\hline
\end{tabular}

Fonte: Autores da pesquisa

Numa segunda etapa, realizou-se a validação semântica do questionário para avaliar o entendimento e a clareza das questões (DeVELLIS, 2003). Para tanto, o questionário foi aplicado junto a uma amostra de 50 universitários de um curso de Administração na região sudeste do Brasil. Esta etapa permitiu que o instrumento de coleta de dados fosse avaliado dentro do perfil do público respondente, sendo que, os resultados permitiram que fossem feitos os ajustes finais antes da efetiva aplicação da pesquisa. Os questionários coletados nesta etapa de validação semântica não foram incluídos na amostra da pesquisa.

Quanto à definição do tamanho mínimo da amostra e para responder de forma adequada a análise do modelo proposto na figura 1, utilizaram-se as recomendações de Ringle, Silva e Bido (2014), que explicam o modo do cálculo e o tamanho de uma amostra/modelo. Assim, o constructo que "recebe mais setas" (preditora) é aquela que decide o tamanho em questão.

Quadro 1b-Questionário utilizado na pesquisa

\begin{tabular}{|c|c|c|}
\hline Constructo & Item & Questão \\
\hline \multirow{6}{*}{ 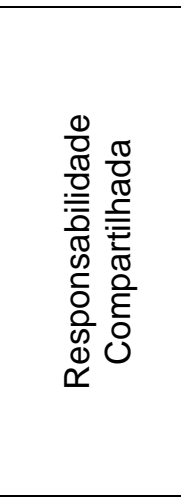 } & Resp_Comp_1 & $\begin{array}{l}\text { A responsabilidade de proteção e conservação do meio } \\
\text { ambiente é exclusiva das empresas }\end{array}$ \\
\hline & Resp_Comp_2 & $\begin{array}{l}\text { As empresas sempre devem ser responsáveis pela logística } \\
\text { reversa de suas embalagens e produtos }\end{array}$ \\
\hline & Resp_Comp_3 & $\begin{array}{l}\text { A responsabilidade de proteção e conservação do meio } \\
\text { ambiente é exclusiva dos cidadãos como eu }\end{array}$ \\
\hline & Resp_Comp_4 & $\begin{array}{l}\text { A responsabilidade de proteção e conservação do meio } \\
\text { ambiente é exclusiva das ONGs }\end{array}$ \\
\hline & Resp_Comp_5 & $\begin{array}{l}\text { O lixo urbano é responsabilidade apenas do órgão de limpeza } \\
\text { urbana }\end{array}$ \\
\hline & Resp_Comp_6 & $\begin{array}{l}\text { A responsabilidade de proteção e conservação do meio } \\
\text { ambiente é exclusiva responsabilidade do governo }\end{array}$ \\
\hline \multirow{5}{*}{ 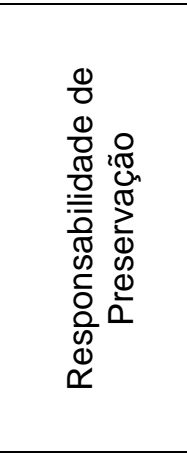 } & Resp_Preserv_1 & $\begin{array}{l}\text { Sempre verifico a origem de produtos de origem florestal que } \\
\text { compro, tais como: lenha, carvão, madeiras em geral }\end{array}$ \\
\hline & Resp_Preserv_2 & $\begin{array}{l}\text { O volume de rejeitos em um processo produtivo significa maior } \\
\text { demanda por matéria prima, consequentemente, maior } \\
\text { exploração de recursos naturais }\end{array}$ \\
\hline & Resp_Preserv_3 & $\begin{array}{l}\text { Compreendo que o tratamento de água e esgoto é fundamental } \\
\text { para a saúde da população }\end{array}$ \\
\hline & Resp_Preserv_4 & $\begin{array}{l}\text { Quando estou em espaços públicos, sempre jogo meu lixo nas } \\
\text { lixeiras }\end{array}$ \\
\hline & Resp_Preserv_5 & $\begin{array}{l}\text { As certificações ambientais indicam que o fabricante apresenta } \\
\text { preocupação com o meio ambiente }\end{array}$ \\
\hline
\end{tabular}




\begin{tabular}{|l|l|l|l|} 
Resp_Preserv_6 & $\begin{array}{l}\text { As atividades humanas tem influenciado as catastrofes } \\
\text { ambientais }\end{array}$ \\
\cline { 2 - 4 } Resp_Preserv_7 & A poluição pode influenciar a qualidade de vida das pessoas \\
\hline Resp_Preserv_8 & $\begin{array}{l}\text { O descarte inadequado de produtos químicos podem contaminar } \\
\text { o meio ambiente }\end{array}$ \\
\cline { 2 - 4 } Resp_Preserv_9 & $\begin{array}{l}\text { Evitar desperdícios dos recursos naturais deve ser um } \\
\text { compromisso de todo cidadão }\end{array}$ \\
\hline
\end{tabular}

Fonte: Autores da pesquisa

Observando a figura, é constatado que todos os constructos recebem uma seta partindo de "Percepção Ambiental". Assim foi utilizado o software G*Power 3.1.7 com as especificações de Cohen (1988) para a área de Ciências Sociais e do Comportamento, isto é, Tamanho do Efeito Médio $(0,15)$, que indica quanto é possível distinguir os constructos e poder do teste de 0,80 (a capacidade de o teste revelar o que ele se propõe a fazer).

Figura 1 - Modelo proposto na pesquisa

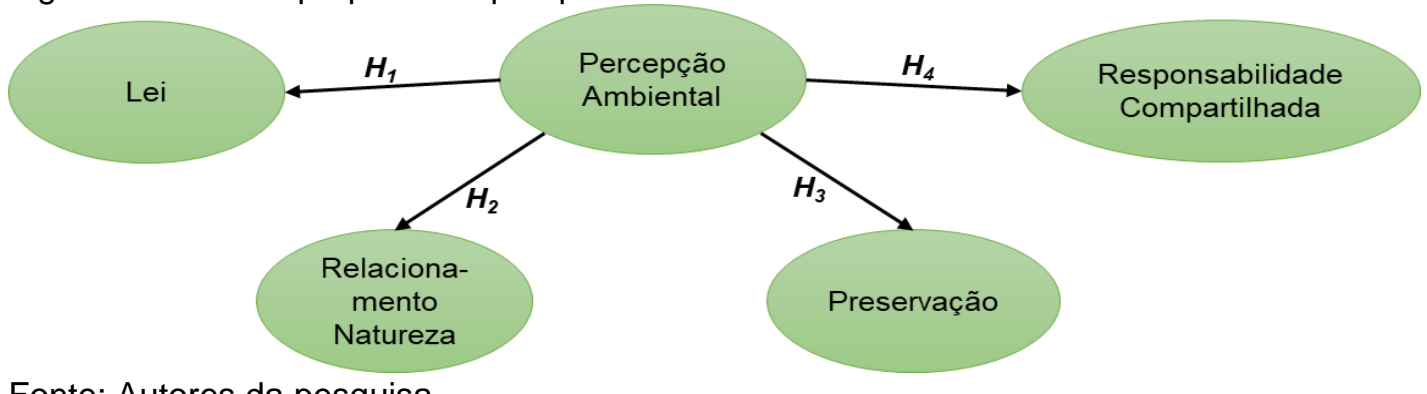

Fonte: Autores da pesquisa

Foi calculada uma amostra mínima de 55 respondentes para o modelo testado na pesquisa. Esta amostra mínima é suficiente para se detectar os efeitos desejados da Modelagem de Equações Estruturais com o Método de Mínimos Quadrados Parciais (Partial Least Square - PLS). Como o total amostrado desta pesquisa foi de 527 respondentes, a amostra ficou 9,58 vezes maior que o tamanho mínimo necessário calculado.

Para as análises descritivas foi usado o software SPSS 22.0 e o software SmartPLS 2.0 - M3, para a Modelagem de Equações Estruturais (MEE) com o Método de Mínimos Quadrados Parciais (Partial Least Square PLS). Foi utilizado para avaliar a consistência do modelo proposto considerado, em todos os testes, o nível de significância ( $\alpha$ ) de 0,05 ou $5 \%$ que é o nível de significância mais recomendado na literatura (HAIR JUNIOR et al., 2005).

Quantos aos critérios de ajuste para validação convergente de modelos que são analisados por meio do PLS-PM foram utilizados os seguintes: 
- O Average Variance Extracted - Variância Média Extraída (AVE): Deve ser superior a 0,50 e avalia se as questões estão correlacionando positivamente em seus respectivos constructos. Assim, quando as AVEs são maiores que 0,50, admite-se que o modelo converge para um resultado satisfatório (FORNELL e LARCKER, 1981; HAIR JUNIOR et al., 2014).

- A Confiabilidade Composta e o Alfa de Cronbach: São critérios que avaliam a correlação interna dos constructos e demonstram o quanto as variáveis "conversam" entre si. Para efeito de ajuste, o valor deve ser maior que $0,70(70 \%)$ de acordo com Hair JUNIOR et al. (2014)

- $R$ quadrado $\left(R^{2}\right)$ : Parte das questões que explicam os constructos e indicam a qualidade do modelo de ajustamento. Para a área de ciências sociais e comportamentais, Cohen (1988) sugere que $R^{2}=2 \%$ seja classificado como efeito pequeno, $R^{2}=13 \%$ como efeito médio e $R^{2}=26 \%$ como efeito grande.

- O tamanho do Efeito ou indicador de Cohen $\left(\mathrm{f}^{2}\right)$ : Avalia como cada construção é "útil" para o ajuste do modelo. Os valores de 0,02, 0,15 e 0,35 são considerados de pequenos, médios e grandes, respectivamente segundo Hair JUNIOR et al. (2014).

- A validade preditiva ou indicador de Stone-Geisse $\left(Q^{2}\right)$ : Avalia a precisão do modelo de ajuste. Os critérios de avaliação são valores maiores que zero (Hair Junior et al., 2014).

Após estes ajustes, deve-se avaliar a validade discriminante do modelo, ou seja, se os constructos explicam coisas diferentes. Para tanto, foi utilizado o critério de Fornell e Larcker, que compara as raízes quadradas dos valores dos AVE's de cada constructo com as correlações dele (Pearson) para com os outros constructos (ou variáveis latentes) (FORNELL; LARCKER, 1981). Segundo os autores, a raiz quadrada dos constructos deve ser maior que o valor de sua correlação com os outros.

Por fim, se avaliou a significância ou p-valor das relações causais (coeficientes de caminho ou de regressão) e das correlações entre as variáveis latentes (constructos) e as variáveis observadas (itens da escala). O recurso do SmartPLS usado foi o módulo "bootstrapping" com 1000 amostragens.

\section{APRESENTAÇÃO E ANÁLISE DOS RESULTADOS}


Após o retorno da avaliação e validação do questionário realizada pelos especialistas, foram feitos os devidos ajustes recomendados e em seguida, classificadas as perguntas de forma aleatória de 1 a 36 e definidas as variáveis categóricas da pesquisa como sendo gênero, renda familiar, faixa etária, estado civil, tipo de universidade (pública ou privada), localização da região do país onde é realizado o curso de graduação, que tipo de instituição foi cursado o ensino médio (pública ou privada).

Considerando estas variáveis categóricas, o perfil dos respondentes ficou formado por $59,7 \%$ pertencem ao gênero feminino e $40,3 \%$ pertence ao gênero masculino. Destes, $74,7 \%$ cursou o ensino médio em escola pública e $21,5 \%$ em escola privada e quanto ao ensino superior $44,8 \%$ dos respondentes realiza sua graduação em universidade pública e 55,2\% em universidade privada.

A faixa etária predominante é de até 25 anos (72,2\%) seguida pela faixa etária de 26 a 35 anos (20,6\%). Quanto à renda familiar, três faixas foram predominantes: até $R \$ 2.000,00$ (36,2\%), de $R \$ 2.001,00$ a $R \$ 3.000,00$ $(24,2 \%)$ e acima de $R \$ 4.000,00(23,1 \%)$. Quanto às regiões do território brasileiro, responderam o questionário $69,1 \%$ do Sudeste, $30,9,4 \%$ do CentroOeste.

Qualificado o perfil da amostra e com os dados obtidos na coleta de dados, foi estimado o modelo reflexivo, no qual os indicadores são as manifestações para cada constructo. Os constructos lei, relação com a natureza, preservação e responsabilidade compartilhada foram classificados como "influenciados" pela construção da Percepção Ambiental e cada um atende a uma hipótese da pesquisa.

Com o modelo definido, foi realizada a primeira rodada de análise no software e, assim, foram descartados os itens com baixa qualidade de ajuste no modelo, isto é, itens com carga fatorial abaixo de 0,50 ou $5 \%$ dentro de seu constructo.

Avaliando os critérios de ajuste, não foi possível considerar o modelo ajustado na primeira rodada, assim, foram realizadas outras rodadas para se buscar o ajuste do modelo que acontece quando todas as variáveis 
apresentam carga fatorial acima de 0,50. Desta forma, não se ajustaram ao modelo as questões "Percep_3"; "Percep_4"; "Percep_5"; "Percep_7"; "Percep_8"; "Percep_9"; "Percep_10"; "Percep_11"; "Lei_1"; "Lei_2"; "Lei_3"; "Lei_4"; "Lei_6"; "Lei_8"; "Rel_Nat_1"; "Resp_Comp_1"; "Resp_Comp_2"; "Resp_Comp_3"; "Resp_Preserv_1"; "Resp_Preserv_2"; "Resp_Preserv_5".

Analisando as questões que não se ajustaram ao modelo, foi observado que o coeficiente de variação estava muito alto ou muito baixo. Este aspecto demonstra que ocorreram casos em que a maioria concordava plenamente ou parte concordava plenamente e parte discordava plenamente, demonstrando que podem ser questões autoevidentes ou de caráter polêmico levando os respondentes a concordância total ou discordância total.

Com as cargas fatoriais ajustadas acima de 0,50 , foram avaliados os outros critérios que definem a qualidade de ajuste do modelo apresentados na tabela 1).

Apesar do Alfa de Cronbach apresentar valores abaixo do valor de referência para dois constructos, este indicador não compromete a validade do modelo, pois este é baseado em intercorrelações e acaba sendo muito sensível ao numero de questões que ficaram ajustadas dentro dos constructos. Para tanto, a Confiabilidade Composta é mais adequada ao PLS-PM, pois prioriza os constructos de acordo com as suas confiabilidades e também permite demonstrar que a amostra está livre de viés (HAIR JUNIOR et al., 2014).

Tabela 1 - Critérios de qualidade de ajuste de modelos de especificação - SEM: Variância Extraída Média (AVE), Confiabilidade Composta, $R^{2}$, Alfa de Cronbach, Validade Preditiva $\left(Q^{2}\right)$ ou indicador de Stone-Geisser e Tamanho do efeito $\left(f^{2}\right)$ ou Indicador de Cohen (1988)

\begin{tabular}{|c|c|c|c|c|c|c|}
\hline Constructo & AVE & $\begin{array}{l}\text { Confiabilidad } \\
\text { e Composta }\end{array}$ & $\mathbf{R}^{2}$ & $\begin{array}{c}\text { Alfa de } \\
\text { Cronbach }\end{array}$ & $\begin{array}{c}\text { Comunalidade } \\
\left(f^{2}\right)\end{array}$ & $\begin{array}{c}\text { Redundância } \\
\left(\mathbf{Q}^{2}\right)\end{array}$ \\
\hline Lei & 0,637 & 0,778 & 0,280 & 0,432 & 0,006 & 0,174 \\
\hline Perc_Amb & 0,509 & 0,757 & ---- & 0,517 & 0,053 & 0,053 \\
\hline Preserv & 0,549 & 0,879 & 0,357 & 0,836 & 0,368 & 0,167 \\
\hline Rel_Nat & 0,729 & 0,843 & 0,227 & 0,633 & 0,219 & 0,156 \\
\hline Res_Comp & 0,536 & 0,775 & 0,092 & 0,570 & 0,104 & 0,042 \\
\hline $\begin{array}{l}\text { Valores de } \\
\text { Referência }\end{array}$ & $>0,50$ & $>0,70$ & $\begin{array}{c}0,02 \\
\text { pequeno } \\
, 0,13 \\
\text { médio e } \\
0,26 \\
\text { grande }\end{array}$ & $>0,60$ & Positivo & Nota 1 \\
\hline
\end{tabular}

Nota 1: Valores de 0,02, 0,15 e 0,35 são considerados, respectivamente, pequeno, médio e grande 
Fonte: Autora da pesquisa.

Além da qualidade do ajuste do modelo, deve-se analisar a validade discriminante, pois os constructos devem se relacionar, contudo, de forma independente (Hair Junior et al., 2014). Usa-se para tal o critério de Fornell e Larcker (1981), conforme apresentado na metodologia deste trabalho e seus valores apresentados na tabela 2.

Tabela 2 - Avaliação da Validade Discriminante - Comparação das raízes quadradas das AVE (em amarelo na diagonal principal) versus correlação entre constructos

\begin{tabular}{cccccc}
\hline & Lei & Percep_Amb & Preserv & Rel_Nat & Resp_Comp \\
\hline Lei & $\mathbf{0 , 7 9 8}$ & & & & \\
Percep_Amb & 0,530 & $\mathbf{0 , 7 1 4}$ & & & \\
Preserv & 0,668 & 0,598 & $\mathbf{0 , 7 4 1}$ & & \\
Rel_Nat & 0,384 & 0,477 & 0,515 & $\mathbf{0 , 8 5 4}$ & \\
Resp_Comp & $-0,320$ & $-0,303$ & $-0,405$ & $-0,180$ & $\mathbf{0 , 7 3 2}$ \\
\hline \multicolumn{7}{l}{ Fonte: Dados da pesquisa } & & &
\end{tabular}

Para todos os constructos, a análise da tabela 2 demonstra que as raízes quadradas das AVE's são maiores que as correlações entre elas. Esse fato determina ao modelo a validade discriminante e a capacidade de ser interpretado. Por fim, com o objetivo de avaliar a qualidade geral do modelo ajustado da pesquisa (figura 2), foi calculado o indicador Goodness-of-Fit (GoF), que é dado pela média geométrica do $\mathrm{R}^{2}$ médio e AVE ponderada média (RINGLE; WENDE; WILL, 2005).

Figura 2 - Modelo ajustado da pesquisa 


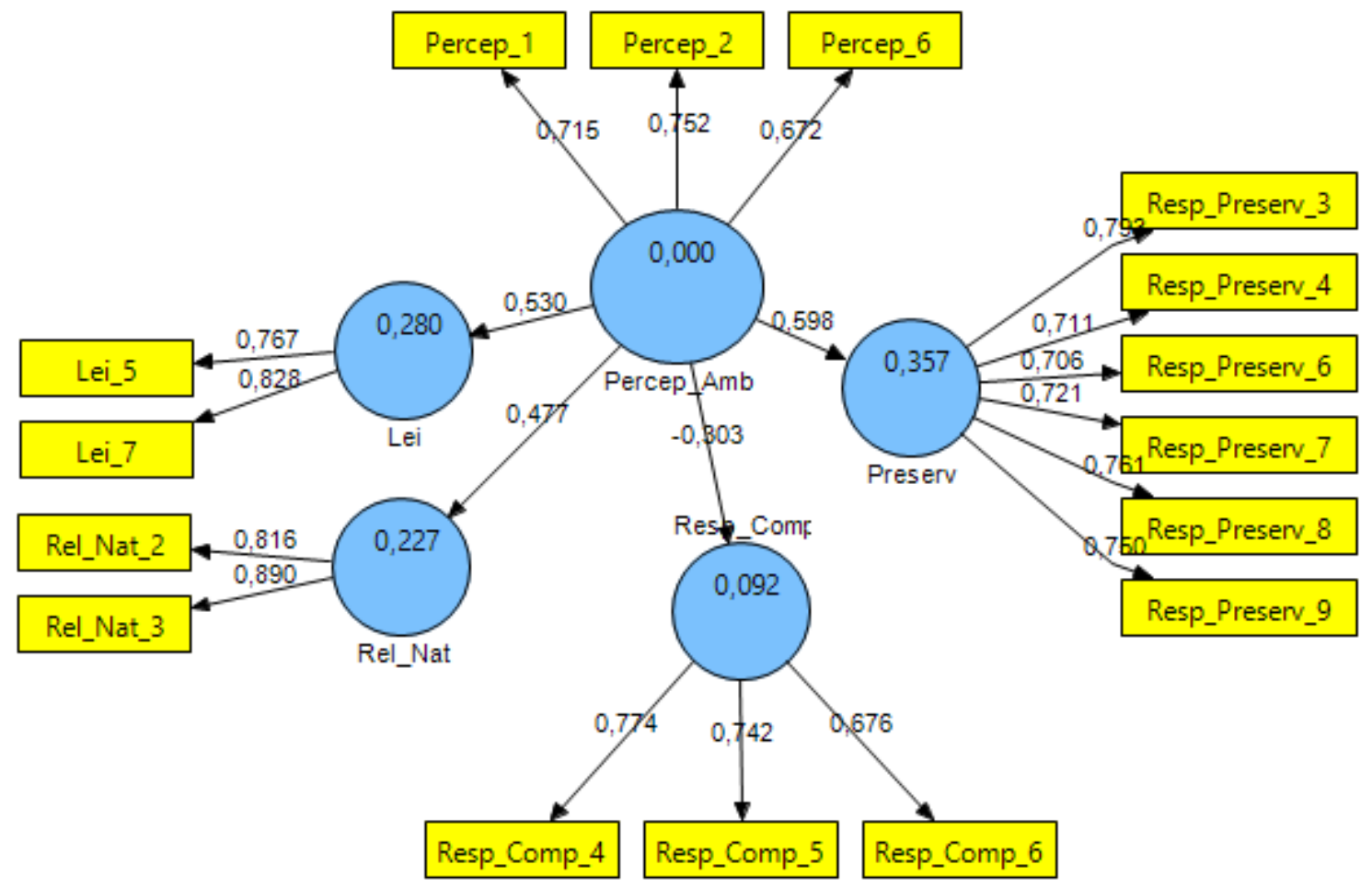

Fonte: Dados da Pesquisa

Nota: Todos os coeficientes de caminho e as cargas fatoriais se mostraram significantes ( $\mathrm{t}>$ 1,96; $p<0,05$ ), tendo sido estimados por meio do método de reamostragem (bootstrap) com $\mathrm{n}=527$ e 1000 repetições (Ringle, Wende \& Will, 2005).

O valor calculado foi de 0,376 e indicou que o modelo pode ser considerado com bem ajustado, uma vez que valores acima de 0,36 são considerados bons para áreas como ciências sociais e comportamentais (Wetzels, Odekerken-Schröder \& Oppen, 2009).

Tabela 3 - Avaliação das hipóteses

\begin{tabular}{lccc}
\hline \multicolumn{1}{c}{ Hipoteses } & Coeficiente de Caminho $(\boldsymbol{\beta})$ & p-valor & Conclusão \\
\hline Percep_Amb $=>$ Lei $\left(\mathbf{H}_{1}\right)$ & 0,530 & 0,043 & Suportada \\
Percep_Amb $=>$ Preserv $\left(\mathbf{H}_{3}\right)$ & 0,598 & 0,044 & Suportada \\
Percep_Amb $=>$ Rel_Nat $\left(\mathbf{H}_{2}\right)$ & 0,477 & 0,048 & Suportada \\
Percep_Amb $=>$ Resp_Comp $\left(\mathbf{H}_{4}\right)$ & $-0,303$ & 0,045 & Suportada \\
\hline
\end{tabular}

Fonte: Dados da Pesquisa

Após a constatação de que o modelo teve um ajuste adequado, pode-se analisar as hipóteses criadas a partir da teoria e que são apresentadas na figura 2. Neste modelo é possível observar o quanto a percepção ambiental dos universitários reflete em cada constructo analisado pelo modelo e, assim, concluir sobre as hipóteses da pesquisa que são apresentadas na tabela 3. 


\subsection{DISCUSSÃO DO MODELO}

Considerando os resultados obtidos por meio da análise dos dados, algumas observações devem ser feitas. Para a percepção ambiental, foi possível notar que a percepção dos universitários está centrada, basicamente, no contexto do consumo consciente, na reciclagem e no uso responsável de energia elétrica. Este aspecto é possível de ser observado pelas questões que prevaleceram no modelo (Percep_1, 2 e 6).

Quanto à hipótese H1 (A Percepção Ambiental dos universitários reflete positivamente no conhecimento das Leis Ambientais), foi confirmada, mas com apenas as questões lei_5 e 7 , que tratam sobre animais silvestres e manutenção de veículos (talvez relacionado a qualidade do ar) demonstrando uma certa fragilidade no conhecimento da legislação.

Quanto à hipótese H2 (A Percepção Ambiental dos universitários reflete positivamente no Relacionamento com a Natureza), pode-se afirmar que 0 contato com a natureza permite que os universitários tenham uma atitude de preservação ambiental mais acentuada, ou seja, sua relação com o meio ambiente é fortalecida e isto contribuiu na construção da percepção ambiental.

Quanto à hipótese H3 (A Percepção Ambiental dos universitários reflete positivamente na preocupação com a Preservação da Natureza), esta demonstra que a preocupação com a preservação ambiental tem uma forte relação com a percepção ambiental e que este aspecto pode está inserida em seu cotidiano.

A hipótese H4 (A Percepção Ambiental dos universitários reflete positivamente na disposição em dividir a responsabilidade ambiental (Responsabilidade Compartilhada)), acabou demonstrando que a percepção ambiental leva em conta que cuidar do meio ambiente é "responsabilidade dos outros", em uma análise descritiva das respostas individuais, foi possível observar que, apesar de grande parte dos universitários discordam que a responsabilidade de pelo lixo urbano e pela proteção e conservação ambiental seja exclusiva do governo (Resp_Comp 5 e 6) ou das ONG's (Resp_Comp 4), eles não assumem que são parte do problema, pois apenas $44 \%$ concordam com a afirmação que ele também é responsavel (Resp_Comp 3). 


\section{CONSIDERAÇÕES FINAIS}

Considerando o objetivo do presente estudo foi possível observar que prevalece na percepção ambiental dos universitários o fato de que os problemas ambientais ainda estão relacionados somente ao consumo de água, de energia e de não jogar lixo no chão. Abordagens mais complexas, onde caberiam reflexões acerca do papel do cidadão na construção de uma sociedade sustentável para não agravar os problemas ambientais, ainda não fazem parte da percepção ambiental destes futuros profissionais e demonstra que "pelo amor" as pessoas ainda não perceberam a importância de se mobilizarem a favor do meio ambiente.

Quanto às hipóteses da pesquisa, percebe-se que para a geração atual, a preservação da natureza é algo apartado do cotidiano de cada indivíduo, e está resumida a "floresta amazônica", ou seja, longe das ações e práticas da vida cotidiana.

No que se refere à legislação ambiental ("pela dor"), verificou-se que apenas os aspectos ligados à caça de animais e manutenção de veículos, aspectos divulgados com maior frequência na mídia, se mantiveram no modelo. Mesmo a legislação ambiental brasileira sendo considerada uma das melhores do mundo, o cidadão não se sente cobrado e parte responsável pela meio ambiente e isto pode ser um ponto crítico.

A pesquisa também demonstrou que o contato com a natureza fortalece a relação de preservação ambiental, o que reforça as teorias a respeito do contato efetivo com a natureza, não a tratando como "peça" de visitação ou ações pontuais de preservação.

Como sugestão futura para outras pesquisas, pode-se avaliar qual a percepção do aluno no ensino médio, como também, avaliar o egresso dos cursos de administração, como uma forma de confirmar que os interesses ou ambiente que se convive podem influenciar na percepção sobre o meio ambiente.

\section{REFERÊNCIAS}


BAKER, M. J. Administração de Marketing. 5. ed. Rio de Janeiro: Elsevier, 2005.

BARBIERI, J. C.; SILVA, D. Educação ambiental na formação do administrador. São Paulo: Cengage Learning, 2012.

BRANDÃO, C. R. O que é educação. São Paulo: Brasiliense, 2006.

BRANDALISE, L. T., BERTOLINI, G. R., ROJO, C. A., LEZANA, Á. G., \& POSSAMAI, O. A percepção e o comportamento ambiental dos universitários em relação ao grau de educação ambiental. Revista Gestão \& Produção, v. 16, n. 2, p. 286-300, 2009.

BRASIL. Constituição (1988). Constituição da República Federativa do Brasil. Brasília, DF: Senado Federal: Centro Gráfico, 1988.

BRASIL, Ministério da Educação e do Desporto, Lei no. 9.795 de 27 de abril de 1999. Dispõe sobre a educação ambiental, institui a Política Nacional de Educação Ambiental e dá outras providências. Diário Oficial da República Federativa do Brasil, Brasília, n. 79, 28 abr. 1999.

BUONO, A. F.; BOWDITCH, J. L. Elementos de comportamento organizacional. São Paulo: Pioneira, 1992.

CASABONA, M. B. et al. O princípio constitucional da solidariedade no direito de família. São Paulo: LEXML, 2007.

CHAUÍ, M. Convite à filosofia. 10. ed. São Paulo: Ática, 2002.

COHEN, J. Statistical Power for Behavioral Sciences. 2 nd. New York: Academic Press, 1998.

COOPER, D. R.; SCHINDLER, P. S. Métodos de pesquisa em administração. 10. ed. São Paulo: Bookman, 2011.

DAVIDOFF, L.F. Introdução à psicologia. São Paulo: Mc Graw-Hill, 2001.

DECLARAÇÃO, DE TBILISI. Conferência Intergovernamental sobre 
Educação Ambiental. Tbilisi, Geórgia: UNESCO, PNUMA, v. 14.

DEVELLIS, R. F. Scale development: theory and applications. Thousand Oaks: Sage Publications, 2003.

DIAS, L. S.; MARQUES, M. D.; DIAS, L. S. Educação, Educação Ambiental, Percepção Ambiental e Educomunicação. In: Leonice Seolin Dias; Antonio Cezar Leal; Salvador Carpi Junior. (Org.). Educação Ambiental: conceitos, metodologia e práticas. 1ed.Tupã/SP: ANAP, 2016, v. 1, p. 12-44.

NASCIMENTO, E. P. Trajetória da sustentabilidade: do ambiental ao social, do social ao econômico. Estudos avançados, v. 26, n. 74, p. 51-64, 2012.

DOWBOR, L. Tendências da gestão social. Saúde e sociedade, São Paulo, v. 8, n. 1, p. 3-16, Feb. 1999.

FARIAS, T. Q. Princípios gerais do direito ambiental. Âmbiento Jurídico, p. 4, 2006.

FARIAS, T.; DA NÓBREGA COUTINHO, F. S.; MELO, G. K. R. Direito ambiental. Jus Podium, 2013.

FORGUS, R. H. Percepção: o processo básico do desenvolvimento cognitivo. São Paulo: Herder, 1971.

FORNELL, C.; LARCKER, D. F. Evaluating structural equation models with unobservable variables and measurement error. Journal of marketing research, p. 39-50, 1981.

HAIR JR, J. F.; BABIN, B.; MONEY, A. H.; SAMOEUL, P.. Fundamentos de Métodos de Pesquisa em Administração. Porto Alegre: Bookman, 2005.

HAIR JR, J. F. et al. A primer on partial least squares structural equation modeling (PLS-SEM). Sage Publications, 2014.

JACOBI, P. Educação ambiental, cidadania e sustentabilidade. Cadernos de pesquisa, v. 118, n. 3, p. 189-205, 2003.

KELSEN, H. Teoria geral do direito e do estado. São Paulo: Martins Fontes, 
2005.

LEONARDI, M.L.A. A educação ambiental como um dos instrumentos de superação da insustentabilidade da sociedade atual. In: CAVALCANTI, C. (Org.) Meio ambiente, desenvolvimento sustentável e políticas públicas. São Paulo: Cortez / Recife: Fundação Joaquim Nabuco. 1997. p. 391-408.

MACEDO, R. L. G. Percepção, conscientização e conservação ambientais. Lavras: UFLA/FAEPE, 2005.

MAIA, N. B.; MARTOS, H. L.; BARRELLA, W. Indicadores ambientais: conceitos e aplicações. São Paulo: Univ Pontifica Comillas, 2001.

MILARÉ, E. Direito do ambiente. 10. ed. rev., atual e ampl. São Paulo: Editora Revista dos Tribunais, 2015.

MORAN, J. M. R. A educação que desejamos: novos desafios e como chegar lá. Campinas: Papirus, 2007.

PORTILHO, F. Sustentabilidade ambiental, consumo e cidadania. 2.ed. São

Paulo: Cortez, 2010.

RINGLE, C. M.; WENDE, S.; WILL, S. SmartPLS 2.0 M3 (Beta). Germany: University of Hamburg, 2005.

RODRIGUES, M. L., MALHEIROS, T. F., FERNANDES, V., \& DAGOSTIN DARÓS, T. A percepção ambiental como instrumento de apoio na gestão e na formulação de políticas públicas ambientais. Saúde e Sociedade, v. 21, p. 96110, 2012.

RODRÍGUEZ, J. M. M.; SEOLIN DIAS, L. (Org.). Educação ambiental em foco. upã: Associação Amigos da Natureza (ANAP), 2014. 182 p.

SAMPIERI, R. H.; COLLADO, C. F.; LUCIO, P. B. Metodologia da pesquisa. 3. ed. São Paulo: McGraw-Hill, 2013.

SAUVÉ, L. Uma cartografia das correntes em educação ambiental. In: SATO, Michèle; SILVA, K. O.; CARVALHO, M. V. C. Meio ambiente e o ensino de geografia-percepção do aluno sobre educação ambiental. Revista de Geografia (Recife), v. 30, n. 2, p. 169-188, 2013. 
TAMAIO, I. A Política Pública de Educação Ambiental. In: Educação Ambiental no Brasil. Ano XVIII boletim 01 - Secretaria de Educação a Distância. MEC, Março de 2008. p. 21-29

TANNER, R. T. Educação ambiental. São Paulo: SUMUS E EDUSP, 1978.

TUAN, Y.-F. Topofilia: um estudo da percepção, atitudes e valores do meio ambiente. Tradução por Lívia de Oliveira. São Paulo; Rio de Janeiro: Difel, 1980.

UNESCO. 1973. A guide to the measurement of marine primary production under some special conditions. Monogr. Oceanogr. Method. 3. UNESCO, Paris. $73 \mathrm{p}$.

VEIGA, A.; AMORIM, E.; BLANCO, M. Um retrato da presença da educação ambiental no ensino fundamental brasileiro: o percurso de um processo acelerado de expansão. Brasília: Instituto Nacional de Estudos e Pesquisas Educacionais Anísio Teixeira, 2005. 